\title{
Elements of a Design Theory of Nano-Viral Messages: A Case Study of \#Solar Nanovirals
}

\author{
Nick V. Flor \\ Marketing, Info. \& Decision Sciences Dept. \\ University of New Mexico \\ nickflor@unm.edu
}

\begin{abstract}
Viral messages reach a large number of people at almost no cost. However, the majority of viral messages are based on shocking or entertaining content. Is it possible to make other kinds of content go viral, such as science and technology news? I use conceptual blending analysis to analyze five representative, very small messages about solar technology that went viral (nanovirals). I identify four distinct viral strategies that vary according to the number of belief systems used, and whether the viral message confirmed or contradicted central beliefs. Finally, I use information systems modeling to depict a common viral mechanism underlying the strategies. I conclude with a practical heuristic to guide the design of nanoviral messages. The key finding is that messages spread virally because they confirm core beliefs in an in-group's shared belief system or they contradict core beliefs in an outgroup's shared belief system.
\end{abstract}

Keywords: viral messages, viral advertising, viral marketing, word-of-mouth, memes, design science, conceptual blending analysis, information systems modeling

\section{Introduction}

One of the challenges that technologists and scientists face is informing the general public about their innovations and discoveries. One solution is to conduct a national advertising campaign. However, for small businesses and most researchers, such campaigns are prohibitively expensive.

One promising, and low-cost alternative to a national advertising campaign is to use viral messages on social media to spread news about innovations and discoveries. Viral messages can reach a wide audience in a relatively short amount of time, with almost no cost except the time needed to develop the message. However, most messages that go viral contain shocking or humorous content.

Figure 1 is an example of a typical viral message with shocking content that was seen by over a hundred thousand individuals in a single day.

The research question I explore in this paper is: can you design a viral message around technology content rather than shocking or entertaining content? Technology content can include announcements of new technology, reports of adoption, and both discoveries of the beneficial uses of technology, as well as findings of the detrimental effects.

To answer the research question, I analyze tiny messages about solar technology that have gone viral. Before describing the method, I review the literature on the 
spreading of viral messages, and briefly clarify my distinction between viral messages and nanovirals.

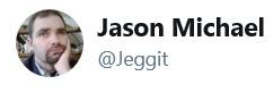

$$
\text { Follow }
$$

Believe it or not, this is a shark on the freeway in Houston, Texas. \#HurricaneHarvy

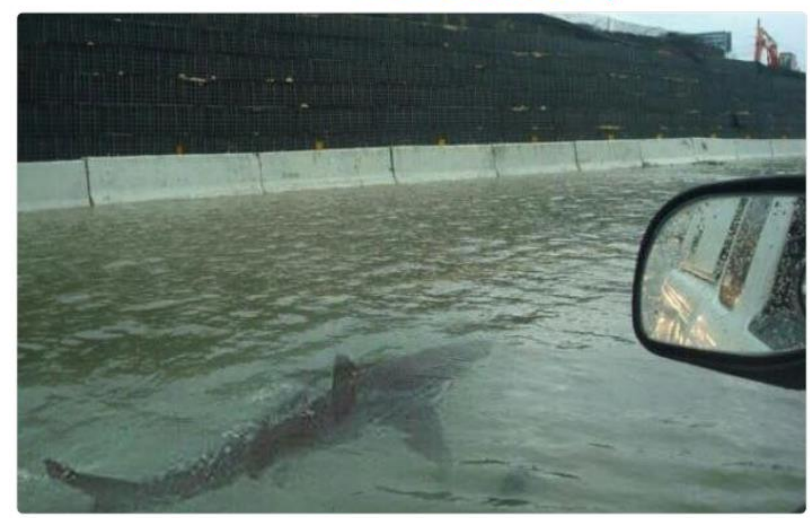

12:00 AM - 28 Aug 2017

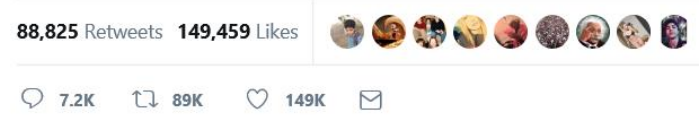

Figure 1. An example of a typical viral message (Michael, 2017).

\section{Literature Review}

Business and management researchers have explored a number of different issues related to sharing viral messages including: motivation (Berger, 2014; Ho and Dempsey, 2010; Pescher, Reichhart, and Spann, 2014); social network characteristics (Bampo, Ewing, Mather, Stewart, and Wallace, 2008; Hinz, Skiera, Barrot, and Becker, 2011; Leskovec, Adamic, and Huberman, 2007; Liu-Thompkins and Rogerson, 2012; Smith, Coyle, Lightfoot, and Scott, 2007); interpersonal factors (Cho, Huh, and Faber, 2014; De Bruyn and Lilien, 2008; Harvey, Stewart, and Ewing, 2011; Hayes, King, and Ramirez, 2016); personality (Chiu, Hsieh, Kao, and Lee, 2007); meta- and para-textual features (Blichfeldt and Smed, 2015; Seo, Li, Choi, and Yoon, 2018); and sharing mechanism details (Aral and Walker, 2011; Schulze, Schöler, and Skiera, 2014).

Particularly relevant to this paper are the attributes of viral content. Message content influences sharing behavior (San Jose-Cabezudo and Camarero-Izquierdo, 2012), with positive attitudes towards an advertisement's content predicting sharing (Ketelaar et al, 2016; Petrescu, Korgaonkar, and Gironda, 2015). More specifically, people share messages with positive content more than negative content, and messages that evoke high-arousal positive or high-arousal negative emotions are shared more than articles that evoke low-arousal emotions (Berger and Milkman, 2012; Heimbach and Hinz, 2016). Messages with strong emotional content including humor, fear, sadness, or inspiration, are more likely to be shared than those evoking other emotions (Phelps, Lewis, Mobilio, Perry, and Raman 2004). 
The positive emotions of awe and affection specifically serve as triggers for active viral sharing (Nikolinakou and King, 2018). Humorous message spread virally and, when coupled with high levels of violence or severe consequences, result in higher ad engagement and a higher chance of sharing (Brown, Bhadury, and Pope, 2010). Generally, messages containing emotional appeals and emotion-evoking strategies are more likely to be shared than information appeals that focus on product features (Akpina and Berger, 2017). Finally, for highly interactive content like games, playfulness increased viral sharing (Zhao and Renard, 2018).

The research in this paper builds on the extant literature, contributing to our understanding of the types of content that go viral, with an emphasis on nanoviral message content. Unlike the majority of the business and management research on viral messages, which use correlational or experimental quantitative methods, I employ a case-based, qualitative method. More case-based research is needed to study social media topics (Gordon, 2016). Technology has given us innovative and unprecedented ways to connect (Wadhwa \& Palvia), and case-based research can discover and document these mechanisms.

\section{Background: Viral Messages and Nanovirals}

A viral message is information that spreads freely from person-to-person within a population often, but not necessarily, via social media. By "freely", I mean that people spread the information naturally - they do not have to be incentivized artificially to do so. A single viral message can reach hundreds of thousands to millions of people (see Figure 1).

Viral messages differ in length. Viral news articles and viral videos are on the high end of the spectrum, and viral messages on micro-blogging, social media platforms like Twitter are on the low-end. My research focuses on very small viral messages, which I call nanoviral messages, or nanovirals for short. Figure 2 is an example of the smallest nanoviral - a single emoji depicting an expressionless face.

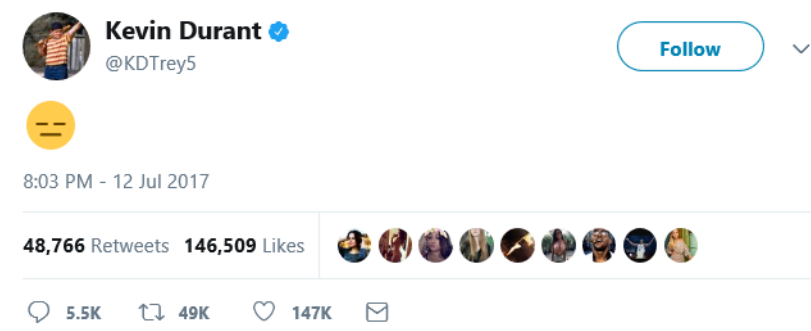

Figure 2. The smallest viral message—a single emoji (Durant, 2017). "Nanovirals" are viral messages less than several hundred characters.

While "very small" is relative, generally, nanovirals are distinguished from longer viral messages in terms of length and operation - their length is typically less than several hundred characters, and they rely more on retrieving existing experiences to generate sudden insight, a process I call apperception shift, when compared to longer viral message which focus on creating an experience in a receiver via comprehension. 
As suggested by Figure 2, where the text is only a single emoji, the key to a message going viral is understanding the subtext of the message. A method is needed that helps discover the subtext from the text of a message.

\section{Method}

One method used in cognitive linguistics for analyzing the underlying meaning, or subtext, of a message is conceptual blending analysis (Fauconnier and Turner, 2002). It is based on the idea that people integrate elements of different beliefs mentally, to arrive at the meaning of a statement. The aim of conceptual blending analysis is to reconstruct how people mentally integrate elements of beliefs to arrive at meanings. In business and management research, it has been applied to analyze consumer aesthetics experience (Joy, Sherry, Mick, and Arnould, 2003), user knowledge in online communities (Flor, 2006), meaning in advertisements (Joy, Sherry, and Deschenes, 2009) and the generation of theories in organizational management (Cornelissen and Durand, 2012; Oswick, Fleming, and Hanlon, 2011). Figure 3 depicts conceptual blending analysis as a hybrid class-communication model.

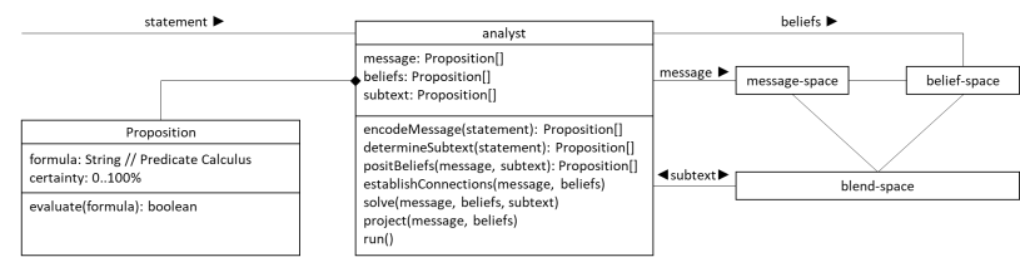

Figure 3. Conceptual blending analysis depicted as a hybrid class-communication model

Briefly, the unit of analysis is a statement. The analyst typically denotes the statement in propositional form, using the rules of predicate calculus. For example, the statement "Fred gave a rock to Wilma" in propositional form would be: Gave(fred, wilma, rock), where Gave is the predicate, and fred, wilma, and rock are terms.

Next, the analyst posits beliefs that the receiver of a message recalls in association with the message. These beliefs are also denoted in propositional form. The beliefs are put in a multi-column table, where each column denotes a mental space. Beliefs that have common (or synonymous) predicates or terms, are said to have a pragmatic connection, and are lined up row-wise in the table. Beliefs with pragmatic connections are special because their elements (predicates and terms) can substitute for one another in the blend.

Finally, the analyst selectively projects beliefs from the mental spaces into the blended space (or simply the "blend") to show the underlying meanings, the various subtexts, of the original statement. The blend is usually the last row in the table. An example should help clarify.

\section{An Example of a Conceptual Blending Analysis}

Table 1 depicts a conceptual blending analysis for the Kevin Durant tweet in Figure 2. The timestamp of the tweet indicates that he posted it during ESPN's annual 
award show, the ESPY. During this show the emcee, Peyton Manning, made fun of Kevin Durant for switching teams in order to win a championship. When the camera panned to Kevin Durant he was not smiling, suggesting that he was mad, but one could not be certain based on the brief camera shot.

Table 1. Conceptual blending analysis for the Kevin Durant single-emoji tweet

\begin{tabular}{|c|c|}
\hline Message (Tweet) Space & Belief (ESPY) Space \\
\hline During(tweet, espy) & $\begin{array}{l}\text { peyton-manning } \\
\text { kevin-durant } \\
\text { P1: MadeFun(peyton-manning, } \\
\text { kevin-durant) } \\
\text { ᄀSmiling(kevin-durant) } \\
\text { R1: P1 \& } \neg \text { Smiling(kevin-durant) } \\
\rightarrow \text { Mad(kevin-durant) }\end{array}$ \\
\hline \multicolumn{2}{|c|}{ BLEND } \\
\hline \multicolumn{2}{|c|}{ 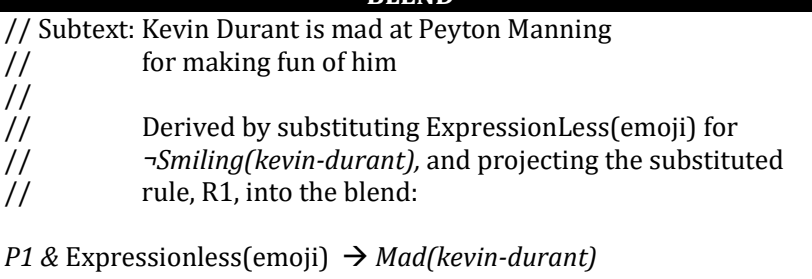 } \\
\hline
\end{tabular}

Propositions representing the message are shown in the left column: the message (tweet) space. Possible beliefs retrieved by a reader, as a consequence of the tweet occurring during the ESPY, are shown in the right column: the belief (ESPY) space. This belief includes the rule that if Kevin Durant is not smiling, he must be mad: ... $\rightarrow$ Smiling(kevin-durant) $\rightarrow$ Mad(kevin-durant). There is a pragmatic connection between the expressionless emoji, ExpressionLess(emoji), and the proposition that Kevin Durant is not smiling, - Smiling(kevin-durant). In the blend, the expressionless emoji is substituted for this proposition, and readers of the tweet conclude that Kevin Durant is mad at Peyton Manning, which confirms their belief from watching the telecast.

Figure 4 depicts conceptual blending analysis as part of an iterative process for generating hypotheses and building theories. While conceptual blending analysis is a qualitative method, and the analyst's descriptions are fundamentally interpretive, by making the interpretations explicit and situating them within a logical framework, like predicate calculus, one can derive hypotheses and theories that are falsifiable and extendible by other researchers. This kind of exploratory research, which concludes with models, hypotheses, and theories, contrasts with confirmatory research, which often starts with models and hypotheses that are informed by existing theories. 


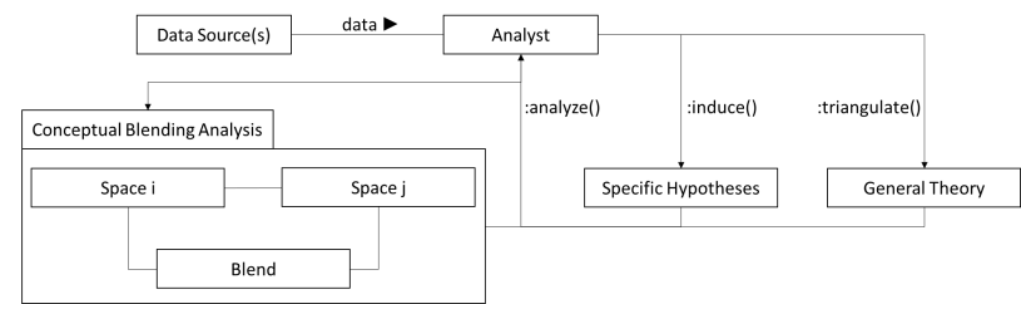

Figure 4. Communication-object diagram depicting conceptual blending analysis as part of an iterative process of hypothesis and theory generation

\section{Data \& Apparatus}

The data analyzed consisted of 330,827 tweets from the social media platform Twitter containing the hashtag \#solar. I used SMEDA (Flor, 2016) as the social media scraping software. SMEDA is a custom module I wrote for Excel that scrapes tweets into an Excel worksheet. In addition to scraping functions, it contains macros for organizing and sorting tweet content, and for building social network edges. SMEDA has been used by researchers in a variety of domains, including augmented reality and video games (Li, Gupta, Zhang, \& Flor, 2018), social media activism (Sanchez, 2018), and e-learning (Gunawardena, Flor, Gomez, \& Sanchez, 2016).

\section{Procedure}

SMEDA was run daily, over a two-month period, from July 1, 2017 to August 31, 2017. A total of 330,827 tweets were collected ( $\mathrm{N}: 330,827 ; \mu: 5335.92$ tweets per day, $\sigma: 1950.40$ ). After the collection period, SMEDA was then used to sort tweets in descending order based on the number of retweets (shares). Tweets containing \#solar, but unrelated to solar technology were thrown out. For example, there was a Korean music group who had a singer named Solar, and who would tag their tweets with \#solar. All such tweets were deleted from the data set analyzed.

\section{Procedure: Operationalizing Viral}

Unlike viral messages containing entertaining or shocking content which receive thousands of retweets, messages with the \#solar hashtag never received over a thousand retweets during the period scraped. Thus, rather than go with an absolute value to classify a tweet as viral, I used a relative measure. Specifically, given the author of a top-sorted tweet, I calculated the mean number of retweets over a week and the standard deviation. If the number of retweets was over one standard deviation, I defined that as viral for that author, and the tweet was analyzed.

Figure 5 depicts the specific hypothesis and theory building process for this research. While conceptual blending analysis is a qualitative method, through iteration and triangulation, viral hypotheses, design heuristics, and falsifiable theories can result. 


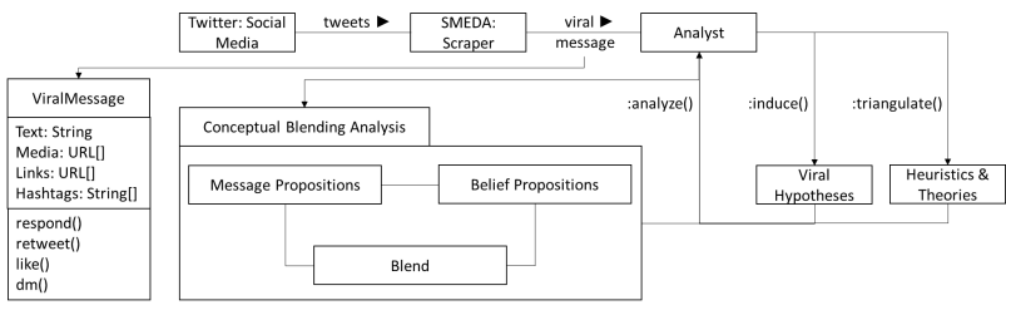

Figure 5. The iterative procedure using conceptual blending analysis on twitter viral messages

It is beyond the scope of this paper to show every top tweet analyzed. Thus, in the results section I present just the analysis of five representatives of the top tweets.

\section{Results}

\section{Representative 1: Fact Confirmation \& Contradiction in Two Different Belief Systems - Progressive Version}

The first tweet analyzed is a finding from the DiCaprio Foundation (@dicapriofdn) about the benefits of the solar industry to employment (see Figure 6). The literal meaning of the text is clear: the solar industry hires more people involved in generating electricity than the fossil fuel industries combined.

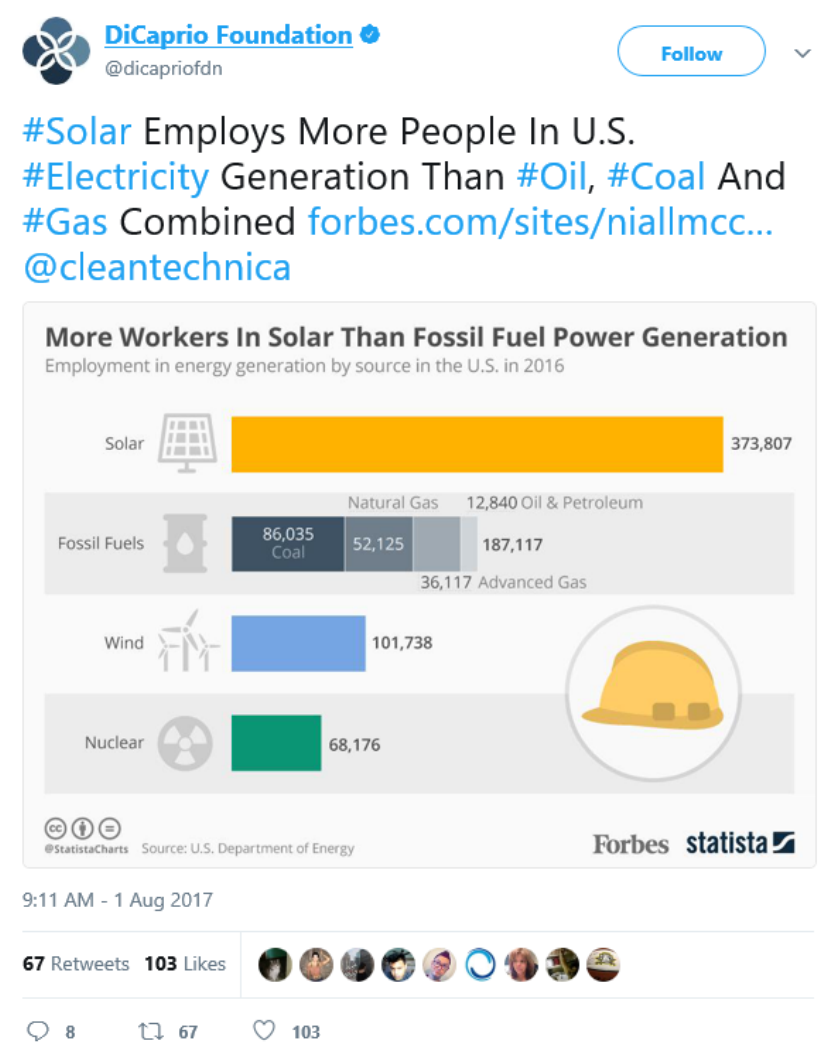

Figure 6. Viral message from @DiCaprioFDN (Dicaprio Foundation, 2017).

The tweet contains: hashtags for solar, electricity, oil, coal, and gas; a link to a Forbes news article for more information; and a user tag for @cleantechnica. The 
text of the tweet is taken from the title of the Forbes article that the tweet links to. Hashtags help spread the tweet to users searching on those tags, and a user tag displays the tweet on that user's mention-timeline. Finally, there is a picture with a bar chart showing the number of people employed in the solar industry versus the fossil fuel industries. The picture sources the data to the Department of Energy.

As described in the method, I use conceptual blending analysis to discover possible subtext underlying the literal meaning of the text (refer to Table 2). The left-hand column contains propositions in predicate calculus form that correspond to the key content of the tweet. The right-hand column contains beliefs, both predicates and propositions (recall propositions are predicates filled-in with values), that the reader of the viral message could recall in association with the text.

For example, the text mentions solar and fossil fuels. It is likely that readers will think of the beliefs of proponents of both solar and fossil fuels. If the reader is a renewable energy proponent, as many progressives are, a common belief is "solar is more important than fossil fuels", or in predicate calculus: Progressive $(p) \rightarrow$ Morelmportant(solar, fossil). The opposite is true if the reader is a fossil-fuel proponent, as many conservatives are: "fossil fuels are more important than solar", Conservative(c) $\rightarrow$ Morelmportant(fossil, solar). A reader may also recall general rules suggested by the text, in this case, "if some product $\mathrm{x}$ is more important than some other product $\mathrm{y}$, more people will be employed making $\mathrm{x}$ than $\mathrm{y}^{\prime \prime}$; in predicate calculus form: Morelmportant $(x, y) \rightarrow$ More(Employed(x), Employed(y)).

Table 2. Conceptual blending analysis for the @DicaprioFdn message

\begin{tabular}{|c|c|}
\hline Message Space & Belief Space \\
\hline $\begin{array}{l}\text { More(Employed(solar), } \\
\text { Employed(fossil)) } \\
\text { Employed(solar, 373K) } \\
\text { Employed(fossil, 187K) }\end{array}$ & $\begin{array}{l}\text { Progressive }(p) \rightarrow \text { MoreImportant } \\
\text { (solar, fossil) } \\
\text { Conservative }(c) \rightarrow \text { MoreImporant } \\
\text { (fossil, solar) } \\
\text { MoreImportant }(x, y) \rightarrow \text { More } \\
(\text { Employed }(x), E m p l o y e d(y))\end{array}$ \\
\hline \multicolumn{2}{|c|}{ Blend Space: Agreement, Disagreement } \\
\hline \multicolumn{2}{|c|}{$\begin{array}{l}\text { // Fact from message } \\
\text { More(Employed(solar), Employed(fossil)) // fact in message } \\
\text { // Subtext 1: Progressives beliefs about solar energy are correct } \\
\text { // via chaining to a proposition that agrees with fact } \\
\text { Progressive(p) } \rightarrow \text { MoreImportant (solar, fossil-fuel) } \rightarrow \text { More (Employed } \\
\text { (solar),Employed(fossil)]// agrees with fact in message }\end{array}$} \\
\hline
\end{tabular}

In the blend space the reader projects the "fact", or more precisely "a proposition with high certainty due to the source", that more people are employed in the solar than in the fossil fuel industry. The reader chains the propositions for both progressives and conservatives, with the general rule about product importance and 
employment, yielding a proposition that agrees with the facts in the case of the progressive belief, and disagrees with the facts in the case of the conservative belief.

Subtext confirming or discrediting widely-held, central beliefs is one of the most common occurrences in nanoviral messages, where I define "central belief" in terms of centrality in a network of propositions - a proposition that occurs in many of the propositional chains that constitute a belief system, c.f., node centrality in social networking theory. I call this the confirm and contradict strategy.

Representative 2: Fact Confirmation \& Contradiction in Two Different Belief SystemsConservative Version

The next example is a discovery of the detrimental effects of solar technology. The example shows a variation of the confirmation and contradiction strategy. @AndrewCFollet's viral message (see Figure 7) is about old solar panels causing environment problems in China. Although lacking details about how the solar panels are causing problems, the literal meaning of the text is clear. The structure of the message is similar to the first one analyzed, namely, the user repeats the headline of an article in the text, includes hashtags, links to an article, and tags users. However, instead of creating hashtags from the title the user specified tcot (Top Conservatives On Twitter), tlot (Top Libertarians On Twitter), and AGW (Anthropogenic Global Warming). The picture caption elaborates on the meaning of "environmental crisis", stating that "Old Solar Panels ... in two or three decades will wreck the environment".

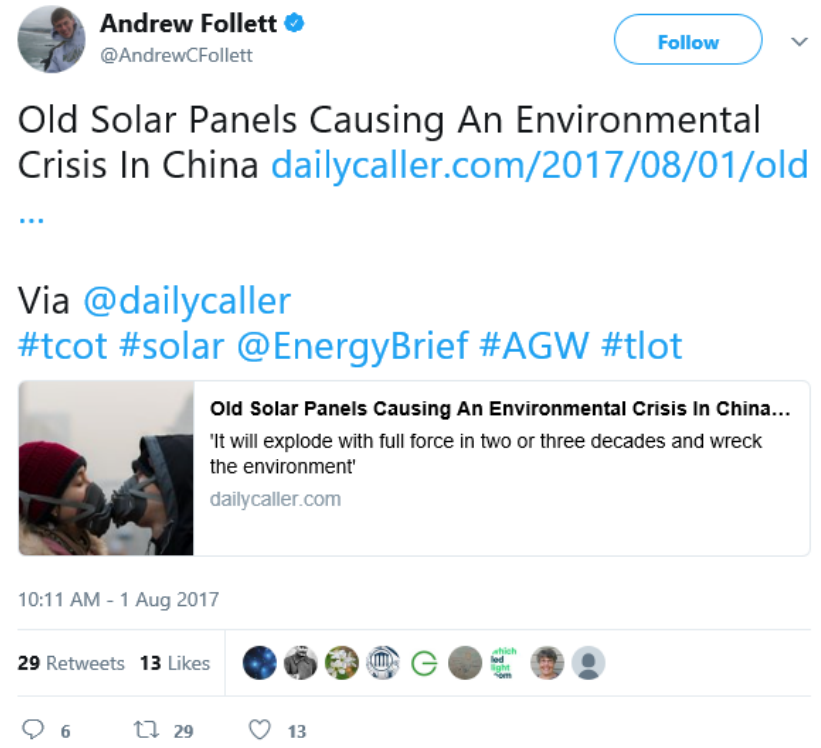

Figure 7. Viral message from @AndrewCFollett (Follett, 2017).

As in the previous analysis, we can represent the key propositions from the message in the left column of our conceptual blending analysis table (refer to Table 3), and possible propositions in the right column. The bottom row blends elements from both columns. The key proposition in the message text is: - Helps(OldSolar(panel), 
Environment(china)). While the predicates Wrecks or Hurts could have been used instead of $\neg$ Helps, it saves time in the analysis from writing synonym propositions.

The possible beliefs include: old solar panels are solar panels; solar panels produce solar energy; progressives believe that solar energy helps the environment; conservatives believe the US should not focus on solar energy; and we should not focus on energy technologies that harm the environment. These beliefs, stated as propositions in predicate form, are in the right column.

Table 3. Conceptual blending analysis for the @AndrewCFollett message

\begin{tabular}{|c|c|}
\hline Message Space & Belief Space \\
\hline $\begin{array}{l}\text { Environment(china) } \\
\text { ᄀHelps (OldSolar(panel), } \\
\text { Environment(china)) }\end{array}$ & $\begin{array}{l}\text { Environment(us) } \\
\text { Old(Solar(panel)) } \rightarrow \text { Solar(panel) } \\
\text { Solar(panel) } \rightarrow \text { Solar(energy) } \\
\text { Progressive }(p) \rightarrow \\
\text { Helps(Solar(energy), } \\
\text { Environment }(\text { us)) } \\
\text { Conservative }(c) \rightarrow \\
\neg \text { Focus }(\text { Solar }(\text { energy)) } \\
\neg \operatorname{Helps~}(x, \text { Environment }(x)) \rightarrow \\
\neg \text { Focus }(x)\end{array}$ \\
\hline \multicolumn{2}{|c|}{ Blend Space: Contradiction \& Confirmation } \\
\hline 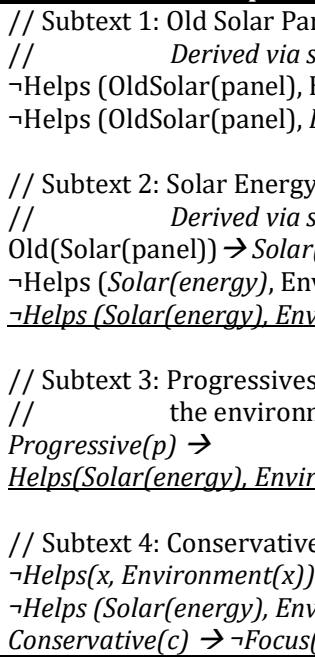 & $\begin{array}{l}\text { help the US environment either } \\
\text { a from fact in Tweet space } \\
\text { nt(china)) } \rightarrow \\
\text { nt(us)) // substitution } \\
\text { p the US environment } \\
\text { a of Solar(Energy) for Solar(Panel) } \\
\text { Solar(energy) } \\
\text { (china)) // substitution } \\
\text { us)] // substitution } \\
\text { gabout solar energy helping } \\
\text { s)) // contradicts Subtext } 1 \\
\text { not to focus on solar energy } \\
\text { (x) } \\
\text { us)) } \rightarrow \text { Foocus(SolarEnergy) } \\
\text { gy) // confirms belief }\end{array}$ \\
\hline
\end{tabular}

In the blend, the subtext includes: solar energy hurts the environment of the United States; progressives are wrong about solar energy benefiting the environment; and conservatives are right not to focus on solar energy. Unlike the previous example, this viral message contains a proposition that contradicts a widely-held progressive belief, while supporting a widely-held conservative one.

Although the details of the blending differ - both chaining propositions and substituting elements of propositions - the outcome of the blending is the same: a confirmation of a central belief in one belief system, and a contradiction of a central belief in another, opposing, belief system. 


\section{Representative 3: Confirmation and Counterfactual in a Single Belief System}

The third example announces the adoption of technology by a city. Some users were particularly adept at creating viral messages. One user, @MikeHudema, often started off his tweets with the phrase "As Trump tweets" (see Figure 8). In this case, the literal meaning of the text, masks complex subtext aimed at denigrating the current president via contrast with a former president. The structure of the tweet is: message, hashtags, link to news article, and picture from news article. The hashtag \#resist refers to a movement consisting of individuals against current-president Trump.

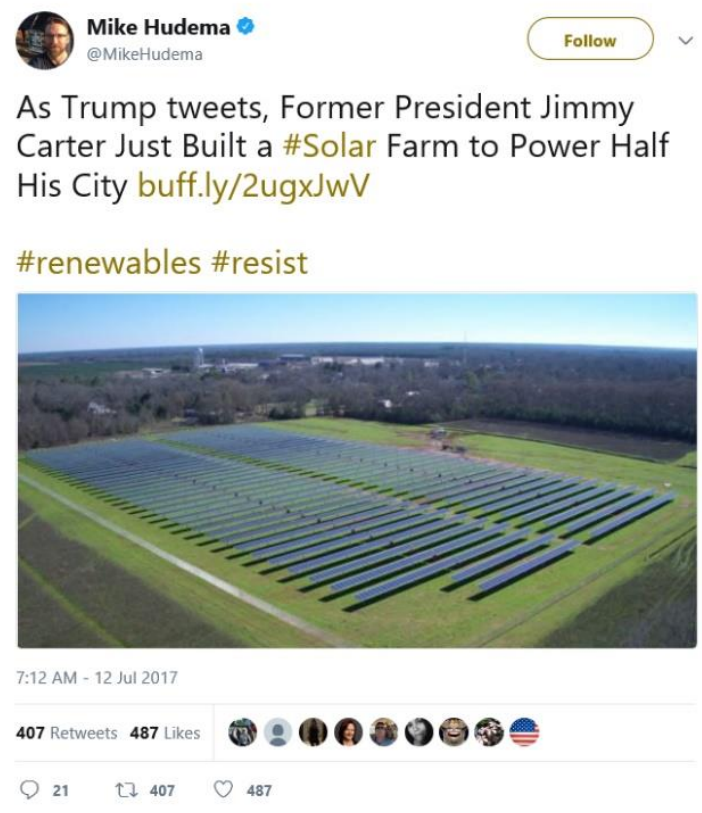

Figure 8. Viral message from @MikeHudema (Hudema, 2017)

In the message space (refer to Table 4, left column), you have two actors, Trump and ex-president Jimmy Carter. There are also propositions that denote Trump tweets, that Jimmy Carter built a solar farm, and that the solar farm powers half the city. In the belief space (right column) you have the fact that Trump is president, and a progressive belief that Trump tweeting is a useless activity. There is a pragmatic connection between the solar farm powering half the city and the city using the solar farm. Finally, you also have the general belief that if someone builds something used by others, then the builder is useful.

Table 4. Conceptual blending analysis for the @MikeHudema message

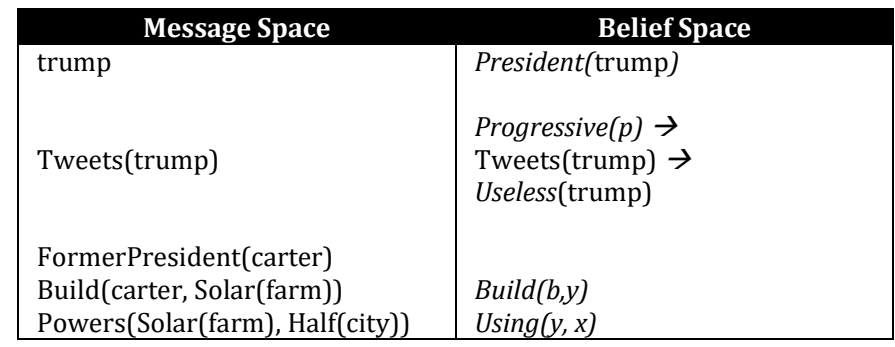




\begin{tabular}{|c|c|}
\hline & $\begin{array}{l}\text { Build }(b, y) \& \text { Using }(y, x) \rightarrow \\
\text { Useful }(b)\end{array}$ \\
\hline \multicolumn{2}{|c|}{ Blend Space: Confirmation \& Counterfactual } \\
\hline \multicolumn{2}{|c|}{$\begin{array}{l}\text { // Subtext 1: Current President is Useless } \\
\text { // } \quad \text { Derived by substitution into Progressive Tweets belief } \\
\text { Progressive }(p) \rightarrow \text { Tweets(trump) } \rightarrow \text { Useless(trump) } \rightarrow \\
\text { Useless(President(trump)) }\end{array}$} \\
\hline \multicolumn{2}{|c|}{ // Subtext 2: Former president jimmy carter is useful } \\
\hline \multirow{2}{*}{\multicolumn{2}{|c|}{$\begin{array}{ll}/ / & \text { Derived by substituting predicate Power for Using } \\
\text { and parameter substitution }\end{array}$}} \\
\hline & ution \\
\hline \multirow{3}{*}{\multicolumn{2}{|c|}{$\begin{array}{l}\text { Build(carter, Solar(farm)) \& Using(Solar(farm), Half(city)) } \rightarrow \\
\text { Useful(carter) } \rightarrow \\
\text { Useful(FormerPresident(carter)) }\end{array}$}} \\
\hline & \\
\hline & \\
\hline \multicolumn{2}{|c|}{ // Subtext 3: if Trump built a solar farm he'd be useful } \\
\hline \multirow{2}{*}{\multicolumn{2}{|c|}{$\begin{array}{ll}/ / & \text { Derived by parameter substitution of Trump for Carter } \\
/ / & \text { and parameter substitution }\end{array}$}} \\
\hline & \\
\hline \multicolumn{2}{|c|}{ Build(trump, Solar(farm)) \& Using(Solar(farm), Half(city)) $\rightarrow$} \\
\hline & \\
\hline
\end{tabular}

The blend contains three pieces of subtext. The first is that the current president is useless, which confirms a progressive belief. This is contrasted with the second subtext, which states that the former president is useful. The second subtext is important because it provides a kind of proof that progressives can cite if challenged on why they believe the current president is useless. Finally, we know that people constantly engage in counterfactual thought, and that it can result in negative emotions like anger and regret (Roese, 1997; Epstude and Roese, 2008). The third subtext is the counterfactual: if current-president Trump had only built a solar farm, he would be useful.

Unlike the previous two examples - which employed two belief systems, confirmations, and a contradictions - this viral message employed a single belief system, confirmations, and a counterfactual. While one may argue that a counterfactual is a contradiction, I reserve the use of counterfactual for those contradictions involving the substitution of people and technologies in action propositions that have positive or negative consequences. I call this the confirmation and counterfactual strategy.

\section{Representative 4: Wrong Economic Belief Indicating Technology Adoption}

The fourth example reports an economic finding and depicts another common type of viral message that employed economic subtext (see Figure 9). The literal meaning is straightforward: renewable energy will be cheaper than fossil fuels across the world in 3 years, according to the Morgan Stanley consulting firm. The structure of this message is like the previous examples, with the exception that the hashtags do not target specific political groups, and no other users are tagged. 
Yes!

Morgan Stanley says \#wind and \#solar will beat \#coal and \#natgas on price in almost every country in 3 years.

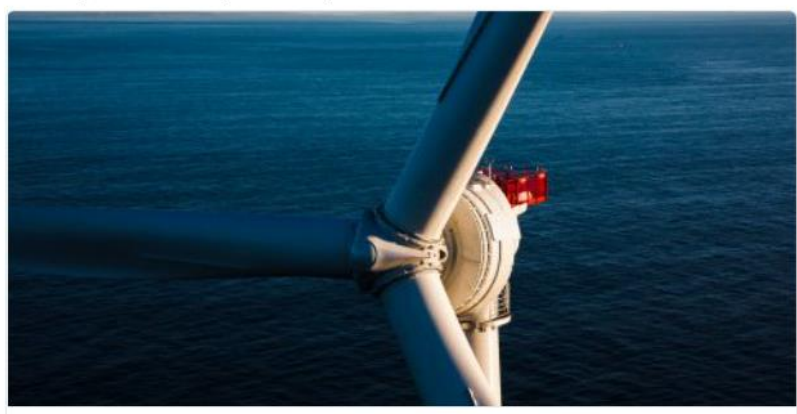

'INFLECTION POINT': Renewables will be the 'cheapest form of new power ge... Wind, solar, geothermal and hydroelectric are on pace to be cheaper than coal in less than three years. businessinsider.com

10:38 AM - 8 Jul 2017

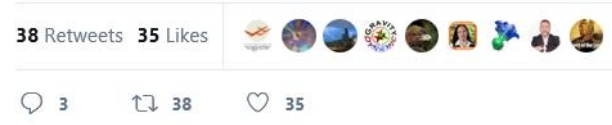

Figure 9. Viral message from @OurCarbon (Ream, 2017).

The message space (refer to Table 5, left column) contains the proposition that the price of wind and solar will be less than the price of price of coal and gas in three years. The belief space (right column) includes the widely-held belief that renewable energies like wind and solar will always be more expensive than fossilfuels, synonyms for renewables and fossil fuels, and the general belief that if the price of two equivalent items are similar, one should adopt the least expensive item.

Table 5. Conceptual blending analysis for the @OurCarbon message

\begin{tabular}{|c|c|}
\hline Message Space & Belief Space \\
\hline $\begin{array}{l}\forall c \in \text { countries, } \mathrm{t} \in \text { date }+3 \text {, } \\
\text { Price (wind, solar, } \mathrm{c}, \mathrm{t})< \\
\text { Price (coal, gas, } \mathrm{c}, \mathrm{t})\end{array}$ & $\begin{array}{l}\forall c \in \text { countries } \\
\text { Price }(\text { wind, solar, c, } \infty)> \\
\text { Price }(\text { coal, gas, } c, \infty) \\
\text { wind, solar }=\text { renewables } \\
\text { coal, gas }=\text { fossil-fuels } \\
\text { Price }(x)<\operatorname{Price}(y) \rightarrow \text { adopt }(x)\end{array}$ \\
\hline & \\
\hline \multicolumn{2}{|c|}{ 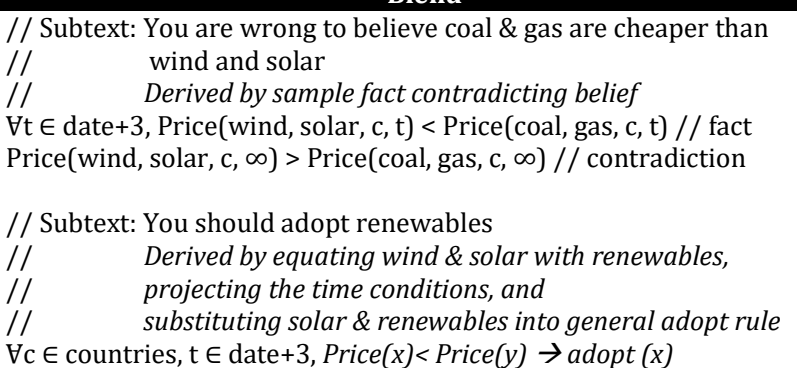 } \\
\hline
\end{tabular}


The blend contains two subtexts. First, that it is wrong to believe coal \& gas will always be cheaper than wind \& solar; second, that renewables should be adopted in three years.

In the case of this viral message, contradicting a widely-held belief leads to a conclusion to adopt a technology. I label this strategy present economic case.

\section{Representative 5: Argument from Majority}

The final kind of viral message that one finds about solar, are those that provide news about other groups of people creating, using, or adopting a technology. In this example it is Australian households adopting solar panels (see Figure 10). The structure of the message is similar to the previous example: text, hashtags, a link to a news article, and a picture.

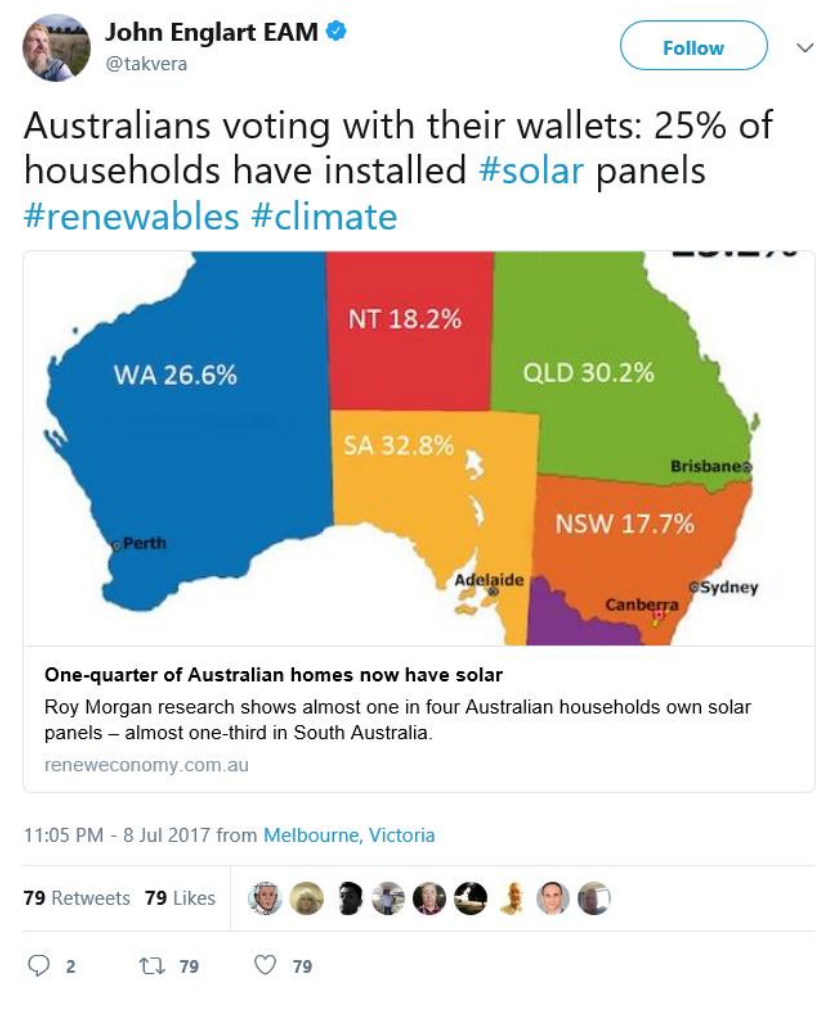

Figure 10. Viral message from @Takvera (Englart, 2017).

In the message space (see Table 6, left column) are the propositions derived from the message, in particular that 25\% Australian households have adopted solar panels. When a person reads such a message, it is natural to think of beliefs that compare or contrast the person's own group to the other group. In predicate calculus this is denoted by substituting predicates and parameters. Since the source group was Australian households, if the reader is American, the reader thinks of American households, and the fact that most American houses do not have solar panels installed. Whether or not this is bad depends on if these households are part of advanced nations, which in the case of Australia and America is true. Finally, there is the general belief that if an advanced nation is behind another advanced 
nation, it should catch up. Table 6, right column, summarizes potential propositions in the belief space.

Table 6. Conceptual blending analysis for the @takvera message (assumes reader is American)

\begin{tabular}{|c|c|}
\hline Message Space & Belief Space \\
\hline Australian(households) & American(households) \\
\hline $\begin{array}{l}\text { Have(Australian (households), } \\
\text { Solar(panels), 25\%) }\end{array}$ & $\begin{array}{l}\text { Have(American (households), } \\
\text { Solar(panels), LessThan }(25 \%)) \\
\text { Have }(x, y, z) \& \\
\text { Have }(a, y, \text { LessThan }(z) \& \\
\text { AdvancedNation }(x) \& \\
\text { AdvancedNation }(a) \rightarrow \\
\text { Behind }(a, x, y) \\
\text { Behind }(a, x, y) \rightarrow \operatorname{Catchup}(a, y)\end{array}$ \\
\hline \multicolumn{2}{|l|}{ Blend } \\
\hline \multicolumn{2}{|c|}{$\begin{array}{l}\text { // Subtext: American households are behind Australian household } \\
/ / \quad \text { in adopting solar panels and should catch up } \\
\text { // } \quad \text { Derived by substitution and chaining } \\
\text { Have(Australian (households), Solar(panels), 25\%) \& } \\
\text { Have(American (households), Solar(panels), LessThan(25\%)) \& } \\
\text { AdvancedNation(Australian (households)) \& } \\
\text { AdvancedNation(American (households)) } \rightarrow \text { Behind(American } \\
\text { (households), Australian (households) Solar(panels)) } \rightarrow \\
\text { Catchup(American(households), Solar(Panels)) }\end{array}$} \\
\hline
\end{tabular}

In the blend, the subtext is that American households are behind Australians in terms of solar panel adoption and, being an advanced nation, should catch up. The viral message creates a new belief based on propositions from the message combined with existing beliefs about progress. I label this strategy the catchup strategy.

\section{Discussion: Strategies \& Common Mechanism}

We have examined five different viral messages that appear to use four seemingly different strategies. Next, we use systems modeling techniques to triangulate to a common underlying viral mechanism that will serve as the basis for a design theory of nanovirals.

\section{Modeling: The Physical Dataflow}

In systems analysis, physical dataflow diagrams depict a system as is, with the agents (both actors and technologies) exchanging data. Initially I assumed a model of viral messages with the following data flow (see Figure 11): 


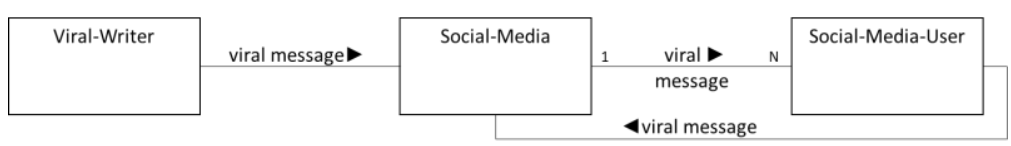

Figure 11. Initial physical dataflow diagram

However, the analysis showed that news about events in the world was a central piece of every viral message. This news, created by some journalist and posted on a news website, can be understood as an input to the viral writer, and a key element of the viral creative process. Figure 12 depicts the revised diagram.

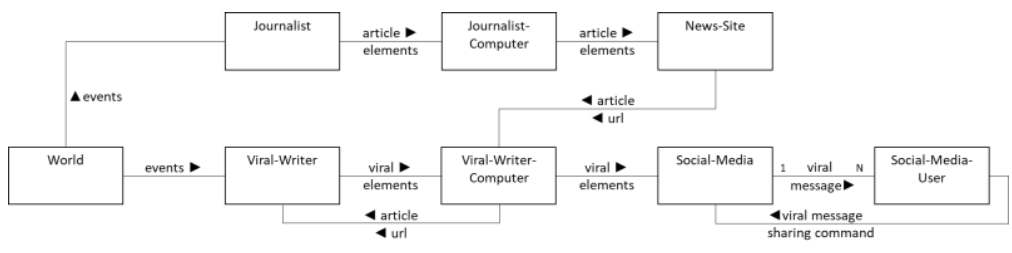

Figure 12. Revised physical dataflow diagram based on the analysis

This revised diagram includes the viral writer's computer because it is a crucial tool used by the writer to search and organize news, as well as to compose the viral message. Note also that the diagram shows viral elements going from the writer to social media rather than a viral message. This is because the analysis made it apparent that social media formatted the final message viewed by users, which included the user's picture and information about date posted, retweets and likes.

From this diagram's inputs and outputs, we can delineate four abstract processes to model: event, news, viral creation, and viral spreading (see Figure 13). Finally, although not depicted explicitly in the process model, social media provides an input to the viral writer, serving as another source in the viral creation process.

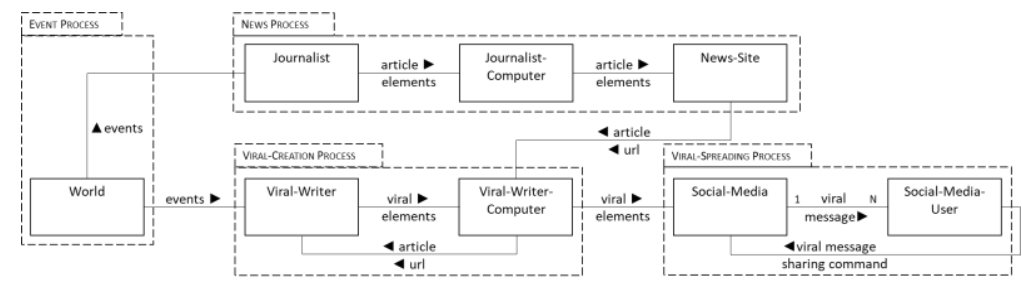

Figure 13. The four processes to model. Messages from social media to the viral writer are implied but not shown.

To help construct a design theory of nanoviral messages, we will model two objects in two separate processes: the social media user in the viral spreading process, and the viral writer in the viral-creation process.

Modeling: The Social Media User in the Viral Spreading Process

Is there a common underlying mechanism in all the viral messages studied, which we can model? The analysis suggests, yes. 
One can represent a viral message as a set of propositions. These propositions, through an associative mental process, retrieve beliefs from belief systems, which one can also represent as propositions.

Some of these beliefs are central to belief systems, e.g., "renewal energy is better than fossil fuel energy" in a progressive belief system, and vice-versa in a conservative belief system. I term such beliefs central beliefs, or central propositions. The intuition is that people use central beliefs to support explanations, predictions or actions. One can use centrality formulas from networking analysis to operationalize this term.

A social media user, given message propositions and central beliefs, will share a message if at least one of the propositions confirms or contradicts a central belief and the social media user determines that the confirmation or contradiction is not shared by his or her followers.

Figure 14 captures the main objects and the main information exchanged between objects.

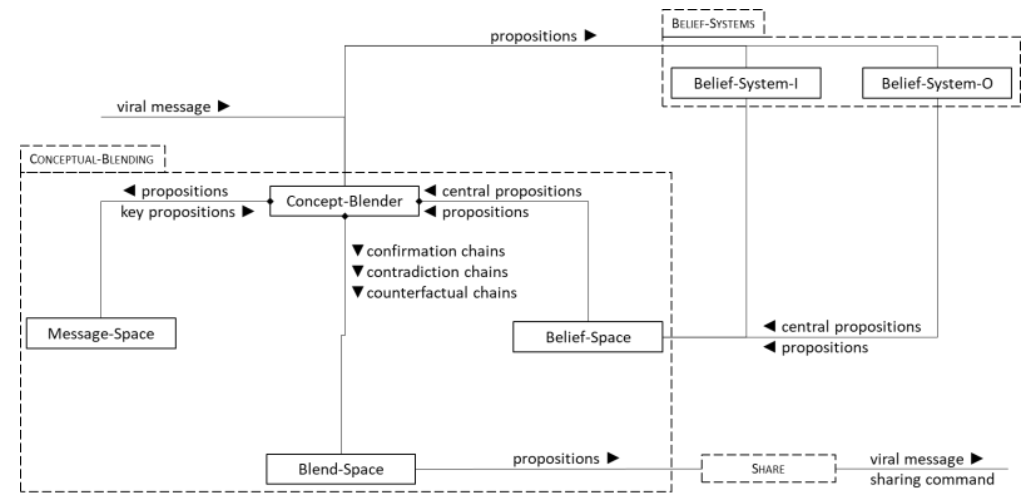

Figure 14. Hybrid class-communication diagram for a social media user. The diagram depicts just two of many possible belief systems.

Once shared, a message will continue to be shared if the belief systems of the followers (the message receivers) are consistent with the those of the sharer. This is likely why there are an abundance of political messages that go viral - progressive and conservative belief systems are consistent across followers, who in turn have followers with those belief systems.

A message can both confirm and contradict central beliefs in separate belief systems, e.g., confirm a progressive belief while simultaneously contradicting a conservative one and vice versa, as the first two analyses showed. The decision rule for sharing is the same: if the sharer believes the confirmation and contradiction is not believed by followers, the message is shared.

\section{Modeling: The Viral Writer in the Viral Spreading Process}

The conceptual blending analysis analyzed the viral messages from the standpoint of a social media user reading them. While we did not analyze the viral creation process, it is possible that the same mechanism for comprehending a viral message, 
is used by a viral message writer to compose a viral message. Comprehension drives composition.

The primary difference is in input and output. An event happens in the world, which the viral writer either experiences directly or learns about via the news or social media. The viral writer represents the events, news, or social media messages as propositions, and if certain propositions confirm or contradict central beliefs, those propositions along with the central beliefs are the ingredients of a potential viral.

The decision to compose a viral message from those ingredients is similar to the sharing decision. A viral writer will create a viral message based on a contradiction or confirmation if the viral writer determines it is not shared by his or her followers.

The process of composing a viral message takes the confirmation or contradiction from the conceptual blending process and adds: supporting links, media (e.g., pictures and videos), user mentions, and hashtags. These viral elements are then sent to social media.

Figure 15 depicts how the viral creation process can leverage the viral spread process. To summarize, the viral message writer contextualizes information from events, from news articles, or from social media messages (that may in turn be viral messages the writer disagrees or agrees with), according to his or her belief systems. The result is a tweet - containing a synthesis of propositions, links, media, mentions, and hashtags - that when read by users may blend a confirmation or contradiction in their own belief systems.

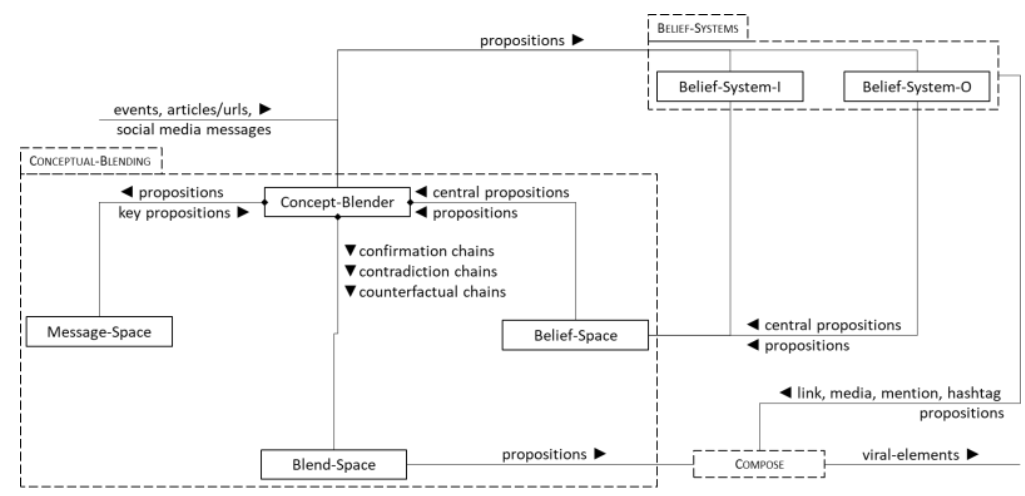

Figure 15. Hybrid class-communication diagram for a viral writer. This composition process leverages the same conceptual blending \& belief systems as the social media user.

Both the model of the user and the model of the viral writer depict conceptual processing, with social media serving as a communication channel for the inputs and outputs of this processing. This leads to the hypothesis that for spreading information about a technology virally, regardless of the specific social media platform, the underlying processes remain the same.

This paper analyzed representative viral messages about one particular technology, solar, with the main finding and hypothesis that messages spread virally because they confirm or contradict central beliefs in a belief system shared by a large number of receivers. The belief systems included political (representatives 1-3), economic 
(representative 4), and national advancement (representative 5). It is not surprising that three of the five representatives leveraged political belief systems, as the adoption of solar energy is a politically sensitive topic, and users with different political affiliations hold different beliefs about the value of solar.

A key question is: does the viral process of confirming or contradicting central beliefs apply to technologies that are less politically sensitive? This is an important question to answer for companies that want to adopt a viral advertising strategy, but do not want to alienate potential customers by posting messages with explicit political content. Although it may be difficult to entirely separate the influence of politics on beliefs, the last two solar representatives analyzed suggest the hypothesis that there are belief systems, which are relatively neutral politically, that one can leverage to promote technology virally. Although neutral, the analyses showed that the confirmation or contradiction of central beliefs was still the common underlying mechanism.

To summarize, this research established that there are ways to make messages spread virally that do not rely on shocking or entertaining content, but rather on content that users interpret as confirming or contradicting central beliefs in a shared belief system. One might ask if there are similarities in process for viral messages containing shocking or entertaining content. An attribute of shocking or entertaining content is unexpectedness, which users would interpret as adding beliefs to an existing belief system. I hypothesize that shocking or entertaining content spreads virally because it adds - versus confirms or contradicts - useful beliefs to shared belief systems.

\section{Conclusion: A Heuristic and Future Research}

In the old days of advertising, copywriters used formulas to help them write ads Attention-Interest-Desire-Action (AIDA) was one, Picture-Promise-Prove-Push (PPPP) was another. There are analogous formulas for writing novels, screen plays, and video games as well.

In the language of design science, these formulas are more properly thought of as "heuristics", because they don't guarantee success so much as they help focus one's effort in generating and in sequencing ideas for composition.

My analysis suggested the following heuristic-Check, Confirm | Contradict, Compose (CCCC):

- Check for news and other events, and based on that news

- Confirm central beliefs in shared belief systems, or

- Contradict central beliefs in shared belief systems.

- Compose viral message around the confirmation or contradiction, adding in hash tags, mentions, media, and links.

The principle underlying the sharing of viral messages seems to be the conservation of consistency in belief systems. Messages are shared because they confirm beliefs that may be uncertain or, in the case of viral messages that show contradictions, 
they point out inconsistencies that must be repaired to maintain a consistent belief system.

Social media managers in firms can adapt the CCCC heuristic to promote technologies by checking news daily for events that contain information, which confirm or contradict central beliefs in the target demographics. Given a confirmation or contradiction, they can compose a viral message around it, using hashtags and @mentions for seeding, along with media and links for more information. The main challenge for social media managers is developing a psychographic profile of the target users' belief systems.

The viral writer model in Figure 15 suggests several areas for future research, which can help expand the theory. The first area is in terms of the source materials used by viral writers. For my \#solar tweets, the source material was always a news article on some website. But the source could be a message read on social media from another user, or an event experienced firsthand, or even a sudden realization of some confirmation or contradiction in one or more belief systems.

The second area of future research is belief systems. How does one determine the content of a group's shared-belief system, and whether an individual is a member of a group? Given the dynamically shifting nature of beliefs, analysts could benefit from automated methods, which determine beliefs systems or group membership, based on user profiles and postings, versus empirical survey methods. Metadata associated with a post, including likes, shares, views, and other engagement data, can help validate potential beliefs. Lastly, the viral messages analyzed in this paper relied on just two belief systems. Studies of viral messages that use more than two belief systems may suggest other viral design strategies.

Process is the third area of future research. The viral rule in the data analyzed was: the confirmation or contradiction of central beliefs. But the data also showed different ways for a news proposition to confirm a central belief, including early and late in a causal chain of propositions. The same was true of contradictions, especially in the use of counterfactual blends. More research is needed in specifying the details through which central beliefs get confirmed or contradicted. Finally, more research is needed to discover other rules beyond confirmation and contradiction, e.g., the connection of central beliefs from different belief systems.

The last area is composition. Future research is needed to clarify steps in this heuristic, especially the composition step. In particular, given a confirmation or a contradiction, or some other rule, what is the best way to state it and to support it with hashtags, mentions, media, and links. More research is needed on the role of hashtags and mentions in making a message go viral, especially if the viral writer does not have a large follower base.

In conclusion, I focused my analysis on viral messages for the hashtag \#solar, in an attempt to discover a way of spreading information virally about science and technologies. I discovered that it was not the existence of a new discovery, or a new innovation that made the news spread, nor was the spread due to a description of how it worked, or what it could do for the reader. Rather, information spread if it confirmed or contradicted widely-held, central beliefs. Furthermore, the belief 
systems may have very little to do with the discovery or innovation, as was the case with the progressive and conservative belief systems, which were political.

Scientists who want to spread discoveries may want to focus less on describing the details of their findings, or less on describing future benefits, and more on how the discovery confirms or contradicts existing, widely-shared belief systems, which may not have much in common with the discovery.

There are many more kinds of viral messages to study: humorous and shocking stories, political messages, picture memes, and many other categories - all far more likely to go viral than technology and science messages. One can use the method in this paper - a combination of conceptual blending analysis and information systems modeling techniques - to analyze these other kinds of viral messages as well and to help build a general theory of viral messages.

\section{Acknowledgments}

This material is based partly upon work supported by the National Science Foundation (NSF) under CMMI -1635334. Any opinions, findings, and conclusions or recommendations expressed in this material are those of the author and do not necessarily reflect the views of the NSF.

\section{References}

Akpinar, E., \& Berger, J. (2017). Valuable virality. Journal of Marketing Research, 54, 318-330.

Aral, S., \& Walker, D. (2011). Creating social contagion through viral product design: A randomized trial of peer influence in networks. Management Science, 57, 1623-1639.

Bampo, M., Ewing, M. T., Mather, D. R., Stewart, D., \& Wallace, M. (2008). The effects of the social structure of digital networks on viral marketing performance. Information Systems Research, 19, 273-290.

Berger, J. (2014). Word of mouth and interpersonal communication: A review and directions for future research. Journal of Consumer Psychology, 24, 586-607.

Berger, J., \& Milkman, K. (2012). What makes online content viral? Journal of Marketing Research, 49, 192-205.

Blichfeldt, B., \& Smed, K. (2015). "Do it to Denmark": A case study on viral processes in marketing messages. Journal of Vacation Marketing, 21, 289-301.

Brown, M., Bhadury, R., \& Pope, N. (2010). The impact of comedic violence on viral advertising effectiveness. Journal of Advertising, 39, 49-66.

Chiu, H., Hsieh, Y., Kao, Y., \& Lee, M. (2007). The determinants of email receivers' disseminating behaviors on the internet. Journal of Advertising Research, 47, 524-534. 
Cho, S., Huh, J., \& Faber, R. (2014). The influence of sender trust and advertiser trust on multistage effects of viral advertising. Journal of Advertising, 43, 100-114.

Cornelissen, J., \& Durand, R. (2012). More than just novelty: Conceptual blending and causality. Academy of Management Review, 37, 152-154.

De Bruyn, A., \& Lilien, G. (2008). A multi-stage model of word-of-mouth influence through viral marketing. International Journal of Research in Marketing, 25, 151163.

Dicaprio Foundation. (2017, August 1). \#Solar Employs More People In U.S. \#Electricity Generation Than \#Oil, \#Coal And \#Gas Combined https://www.forbes.com/sites/niallmccarthy/2017/01/25/u-s-solar-energyemploys-more-people-than-oil-coal-and-gas-combinedinfographic/\#24349f3e2800 ...@cleantechnicapic.twitter.com/vU2z2u4EFn [Tweet]. Retrieved May 28, 2019, from @dicapriofdn website: https://twitter.com/dicapriofdn/status/892417404428460032

Durant, K. (2017, July 12). $\ominus$ [Tweet]. Retrieved May 28, 2019, from @KDTrey5 website: https://twitter.com/KDTrey5/status/885318651728904192

Englart, J. (2017, July 8). Australians voting with their wallets: $25 \%$ of households have installed \#solar panels \#renewables \#climate http://reneweconomy.com.au/one-quarter-of-australian-homes-now-havesolar-70886/ ... [Tweet]. Retrieved May 28, 2019, from @takvera website: https://twitter.com/takvera/status/883929972812808193

Epstude, K., \& Roese, N. J. (2008). The functional theory of counterfactual thinking. Personality and Social Psychology Review, 12, 168-192.

Fauconnier, G., \& Turner, M. (2002). The way we think: Conceptual blending and the mind's hidden complexities. New York: Basic Books.

Flor, N. (2006). Addressing the problem of content restrictions in online community forums. Journal of Information Technology Case and Application Research, 8, 733.

Flor, N. (2016). SMEDA - Social Media Exploratory Data Analytics Software. GitHub Repository, https://github.com/professorf/smeda

Follett, A. (2017, August 1). Old Solar Panels Causing An Environmental Crisis In China http://dailycaller.com/2017/08/01/old-solar-panels-causing-anenvironmental-crisis-in-china/?utm_source=site-share ... Via @dailycaller \#tcot \#solar @EnergyBrief \#AGW \#tlot [Tweet]. Retrieved May 28, 2019, from @AndrewCFollett website: https://twitter.com/AndrewCFollett/status/892432713667547136

Gordon, S. (2016). Prospects for case-based research on social media. Journal of Information Technology Case and Application Research, 18, 193-199. 
Gunawardena, C. N., Flor, N. V., Gómez, D., \& Sánchez, D. (2016). Analyzing social construction of knowledge online by employing interaction analysis, learning analytics, and social network analysis. Quarterly Review of Distance Education, $17,35-60$.

Harvey, C., Stewart, D., \& Ewing, M. (2011). Forward or delete: What drives peer-topeer message propagation across social networks? Journal of Consumer Behaviour, 10, 365-372.

Hayes, J., King, K., \& Ramirez, A. (2016). Brands, friends, \& viral advertising: A social exchange perspective on the ad referral processes. Journal of Interactive Marketing, 36, 31-45.

Heimbach, I., \& Hinz, O. (2016). The impact of content sentiment and emotionality on content virality. International Journal of Research in Marketing, 33, 695-701.

Hinz, O., Skiera, B., Barrot, C., \& Becker, J. (2011). Seeding strategies for viral marketing: An empirical comparison. Journal of Marketing, 75, 55-71.

Ho, J., \& Dempsey, M. (2010). Viral marketing: Motivations to forward online content. Journal of Business Research, 63, 1000-1006.

Hudema, M. (2017, July 12). As Trump tweets, Former President Jimmy Carter Just Built a \#Solar Farm to Power Half His City http://buff.ly/2ugxJwV \#renewables \#resistpic.twitter.com/6Kv0cVhLmo [Tweet]. Retrieved May 28, 2019, from @MikeHudema website: https://twitter.com/MikeHudema/status/885139695377797121

Joy, A., Sherry, J., \& Deschenes, J. (2009). Conceptual blending in advertising. Journal of Business Research, 62, 39-49.

Joy, A., Sherry Jr., J., Mick, D., \& Arnould, J. (2003). Speaking of art as embodied imagination: A multisensory approach to understanding aesthetic experience. Journal of Consumer Research, 30, 259-282.

Ketelaar, P., Janssen, L., Vergeer, M., van Reijmersdal, E., Crutzen, R., \& van 't Riet, J. (2016). The success of viral ads: Social and attitudinal predictors of consumer pass-on behavior on social network sites. Journal of Business Research, 69, 26032613.

Leskovec, J., Adamic, L., \& Huberman, B. (2007). The dynamics of viral marketing. ACM Transactions on the Web, 1, 1-46.

Li, H., Gupta, A., Zhang, J., \& Flor, N. (in press). Who will use augmented reality? An integrated approach based on text analytics and field survey. European Journal of Operational Research.

Liu-Thompkins, Y., \& Rogerson, M. (2012). Rising to stardom: An empirical investigation of the diffusion of user-generated content. Journal of Interactive Marketing, 26, 71-82. 
Michael, J. (2017, August 27). Believe it or not, this is a shark on the freeway in Houston, Texas. \#HurricaneHarvypic.twitter.com/ANkEiEQ3Y6 [Tweet]. Retrieved May 28, 2019, from @Jeggit website: https://twitter.com/Jeggit/status/902048241646280704

Nikolinakou, A., \& King, K. W. (2018). Viral video ads: Emotional triggers and social media virality. Psychology \& Marketing, 35, 715-726.

Oswick, C., Fleming, P., \& Hanlon, G. (2011). From borrowing to blending: Rethinking the processes of organizational theory building. Academy of Management Review, 36, 318-337.

Pescher, C., Reichhart, P., \& Spann, M. (2014). Consumer decision-making processes in mobile viral marketing campaigns. Journal of Interactive Marketing, 28, 43-54.

Petrescu, M., Korgaonkar, P., \& Gironda, J. (2015). Viral advertising: A field experiment on viral intentions and purchase intentions. Journal of Internet Commerce, 14, 384-405.

Phelps, J., Lewis, R., Mobilio, L., Perry, D., \& Raman, N. (2004). Viral marketing or electronic word-of-mouth advertising: Examining consumer responses and motivations to pass along email. Journal of Advertising Research, 44, 333-348.

Ream, T. (2017, July 8). Yes! Morgan Stanley says \#wind and \#solar will beat \#coal and \#natgas on price in almost every country in 3 years.http://www.businessinsider.com/solar-power-energy-renewablescheapest-power-says-morgan-stanley-2017-7 ... [Tweet]. Retrieved May 28, 2019, from @ourcarbon website: https://twitter.com/ourcarbon/status/883742030072922112

Roese, N. (1997). Counterfactual thinking. Psychological Bulletin, 121, 133-148.

Sánchez, D. (2018). Concientization among people in support and opposition of President Trump. Educational Technology \& Society, 21, 237-247.

San Jose-Cabezudo, R., \& Camarero-Izquierdo, C. (2012). Determinants of openingforwarding e-mail messages. Journal of Advertising, 41, 97-112.

Schulze, C., Schöler, L., \& Skiera, B. (2014). Not all fun and games: viral marketing for utilitarian products. Journal of Marketing, 78, 1-19.

Seo, Y., Li, X., Choi, Y., \& Yoon, S. (2018). Narrative transportation and paratextual features of social media in viral advertising. Journal of Advertising, 47, 83-95.

Smith, T., Coyle, J., Lightfoot, E., \& Scott, A. (2007). Reconsidering models of influence: The relationship between consumer social networks and word-ofmouth effectiveness. Journal of Advertising Research, 47, 387-397.

Wadhwa, V., \& Palvia, S. (2018). Is information technology hacking our happiness? Journal of Information Technology Case and Application Research, 20, 151-157. 
Zhao, Z., \& Renard, D. (2018). Viral promotional advergames: How intrinsic playfulness and the extrinsic value of prizes elicit behavioral responses. Journal of Interactive Marketing, 41, 94-103.

\section{Notes on contributors}

Nick Flor is an Associate Professor of Information Systems at the University of New Mexico, in the Anderson School of Management's Department of Marketing, Information Systems, Information Assurance, and Operations Management. His research applies cognitive methods, exploratory data analytics, and visualizations to study viral processes, informal learning, and dynamic organization on social media. Dr. Flor's work is published in journals, which include Communications of the ACM, International Journal of Human-Computer Studies, and Knowledge-Based Systems. He is author of the book Web Business Engineering by Addison-Wesley publishing. Dr.

Flor is principal or co-principal investigator on several Federal Grants, sponsored by the National Science Foundation, the Defense Intelligence Agency, and Sandia National Labs. He is director of the Research Analytics \& Virtual Environments Laboratory at UNM. Dr. Flor holds a PhD in Cognitive Science from the University of California San Diego. 